\title{
Investimento, estrutura produtiva e inserção externa: breves considerações teóricas sobre padrões sustentados de crescimento de economias em desenvolvimento ${ }^{1}$
}

Roberto Alexandre Zanchetta Borghi ${ }^{2}$

Resumo: Este artigo busca contribuir para o debate sobre trajetórias sustentadas de crescimento de economias em desenvolvimento a partir de um arcabouço teórico alternativo aos argumentos econômicos convencionais. Baseada em contribuições pós-keynesianas, estruturalistas e desenvolvimentistas, a análise reitera o papel central do investimento como força motriz da atividade econômica, dada sua importância como componente da demanda agregada e promotor de mudanças estruturais necessárias aos padrões produtivos de economias em desenvolvimento. Tais considerações são realizadas à luz da inserção externa dos países, na qual cumprem papel decisivo as políticas nacionais que possivelmente desenvolvam a estrutura produtiva doméstica a fim de garantir padrões sustentados de crescimento econômico.

Palavras-chave: Crescimento econômico. Investimento. Estrutura produtiva. Inserção externa.

Classificação JEL: E12; F43; O11.

Abstract: This paper aims to contribute to the debate on sustained growth trajectories of developing economies from an alternative theoretical framework to conventional economic arguments. Based on Post Keynesian, Structuralist and Developmental contributions, the analysis highlights the central role played by investment as driving force of economic activity, given its importance as component of aggregate demand and leading factor of structural changes necessary to productive patterns of developing economies. Such considerations are made in the light of countries' international insertion, to which national policies that possibly upgrade the domestic productive structure play a key role in order to assure sustained patterns of growth.

Keywords: Economic growth. Investment. Productive structure. International insertion.

\section{Introdução}

A temática do crescimento econômico está presente na maioria dos debates atuais sobre diversas economias. Economistas e formuladores de política econômica sempre estiveram preocupados a respeito das forças motrizes da atividade econômica. No entanto, este tema ainda permanece bastante controverso. Um ponto recente de discussão têm sido as diferentes explicações sobre trajetórias sustentadas de crescimento a partir do fenômeno da globalização, isto é, da abertura dos mercados domésticos e da maior liberdade concedida aos fluxos internacionais de comércio e de capitais. Essa discussão ganha destaque na comparação entre as experiências asiáticas e latino-americanas.

Este artigo procura lançar luz sobre a temática do crescimento, tecendo considerações teóricas fundamentais para entender trajetórias sustentadas de crescimento de economias em

\footnotetext{
${ }^{1} \mathrm{O}$ autor agradece à Capes pelo auxílio financeiro na condução desta pesquisa, que é resultado parcial de sua Tese de Doutoramento. Trata-se de uma versão enxuta de algumas discussões teóricas apresentadas em seu trabalho de tese.

2 Doutorando da Universidade de Cambridge, Reino Unido. Mestre pelo Instituto de Economia da Universidade Estadual de Campinas (Unicamp). \razb2@cam.ac.uk.
} 
desenvolvimento. Baseada em contribuições pós-keynesianas, estruturalistas e desenvolvimentistas, a análise reitera o papel central do investimento como força motriz da atividade econômica, dada sua importância como componente da demanda agregada e promotor de mudanças estruturais necessárias aos padrões produtivos de economias em desenvolvimento. Tais considerações são realizadas à luz da inserção externa dos países, na qual cumprem papel decisivo as políticas nacionais que possivelmente desenvolvam a estrutura produtiva doméstica a fim de garantir padrões sustentados de crescimento econômico. Essas ideias contrapõem-se aos argumentos econômicos convencionais de que a liberalização indiscriminada dos fluxos de comércio e de capitais resultaria necessariamente em taxas de crescimento mais elevadas.

O artigo encontra-se dividido em duas breves seções, além dessa introdução e das considerações finais. Na primeira seção, destaca-se o papel da demanda e, sobretudo, do investimento enquanto motor do crescimento econômico. Discute-se, ainda, a importância da estrutura de oferta como forma de garantir maior crescimento doméstico. Na segunda seção, à luz do debate sobre crescimento entre economias asiáticas e latino-americanas, enfatiza-se a necessidade das políticas nacionais para promover formas de inserção externa que fortaleçam o investimento e as estruturas produtivas domésticas.

\section{Investimento e estrutura produtiva: uma perspectiva pós-keynesiana e estruturalista sobre o crescimento econômico}

O investimento é, reconhecidamente, uma variável-chave do processo de criação de renda do sistema econômico. Keynes (1936) advertia que o nível de atividade econômica - leia-se, emprego e renda - é dado pelo nível de gasto na economia. A demanda, portanto, cumpria papel fundamental em seu arcabouço, uma vez que decisões de gasto - ou demanda - gerariam, a partir de seus efeitos multiplicadores sobre o restante da economia, um círculo virtuoso de crescimento.

Este é um dos pressupostos fundamentais do arcabouço teórico pós-keynesiano ${ }^{3}$. Contudo, dentre os componentes de demanda agregada, que contribuem para o processo de crescimento e incluem consumo, investimento, gastos governamentais e demanda externa, o investimento sobressai enquanto determinante de trajetórias sustentadas de crescimento econômico.

A importância do investimento reside não apenas em seus efeitos sobre o sistema econômico enquanto fonte de demanda, mas também em sua capacidade única de transformar a estrutura produtiva, de modo a garantir uma resposta adequada da oferta doméstica aos estímulos de demanda. Faz-se mister salientar, portanto:

\footnotetext{
${ }^{3}$ Ver King (2002 e 2012), Pasinetti (2007), Davidson (2011) e Harcourt \& Kriesler (2013a e 2013b).
} 
(i) Seu papel como demanda corrente, mas prospectiva. A demanda por investimento envolve a expansão ou criação de capacidade produtiva considerando as expectativas de demanda futura que devem cobrir o montante investido. Contudo, uma vez realizado, o investimento produz um aumento corrente na renda por meio da provisão dos insumos e equipamentos de que necessita para ser efetivado bem como dos efeitos multiplicadores sobre a produção de outros setores da economia.

(ii) Seu período de maturação e seus efeitos de mais longo prazo. O investimento leva, em geral, mais tempo do que uma simples unidade de produção para ser executado. Logo, representa uma demanda contínua para a produção de outros bens durante um período mais longo de tempo. Isto significa que o investimento não apresenta apenas efeitos sobre a renda corrente, mas também sobre o sistema econômico como um todo no longo prazo. Em decorrência disso, seus efeitos multiplicadores devem ser maiores do que de qualquer outra categoria de consumo corrente.

(iii) Sua escala. A escala do investimento também é maior quando comparada a de outros estímulos de demanda, uma vez que o montante de capital requerido para realizar o investimento é consideravelmente elevado. Como fonte de demanda, isto representa, em termos absolutos, mais demanda por produção intermediária, níveis mais elevados de renda e, consequentemente, mais demanda por bens de consumo em geral.

(iv) Mudanças estruturais que ele acarreta. A demanda por investimento possui a capacidade de promover mudanças estruturais no sistema produtivo doméstico. Representa, assim, a principal fonte de mudança na estrutura econômica em direção ao fortalecimento de encadeamentos produtivos domésticos que, por sua vez, conduzem a um maior nível de renda e produto na economia como um todo. Como o investimento é indispensável para a consolidação ou expansão de qualquer indústria, torna-se a base para a promoção de uma estrutura produtiva diversificada e integrada e, logo, condição necessária para o crescimento econômico sustentado.

Dadas todas essas características, não é por acaso que o investimento está no centro da teoria pós-keynesiana. Como Keynes (1937) ressaltava, o investimento é a causa causans do nível de produto e emprego da economia como um todo. No entanto, como outras decisões econômicas, as decisões de investimento também estão imbuídas de incerteza e, portanto, são tomadas a partir de 
expectativas a respeito do futuro de variáveis consideradas influentes sobre o processo decisório bem como do grau de confiança dos tomadores de decisão nessas expectativas ${ }^{4}$.

Uma vez que as decisões de investimento são centrais para a determinação de um nível mais elevado de atividade econômica, todavia estão suscetíveis a amplas flutuações, o intervencionismo estatal é considerado um meio para promoção do crescimento econômico, seja diretamente por meio de gastos governamentais, seja indiretamente por meio de incentivos de política econômica para o investimento privado. Nesse sentido, o Estado cumpre importante papel em coordenar os investimentos entre os agentes econômicos e em estabelecer um regime econômico favorável ao investimento ${ }^{5}$.

Os estímulos de demanda e seus efeitos multiplicadores são, portanto, essenciais para promoção de crescimento econômico. Entretanto, faz-se necessária uma estrutura de oferta capaz de assegurar que esses estímulos se traduzam em maior crescimento doméstico. A literatura estruturalista e pós-keynesiana-kaldoriana ressalta como os efeitos multiplicadores de renda gerados a partir das decisões de gasto (ou demanda) dependem da organização doméstica da produção em termos de sua composição setorial, encadeamentos interindustriais e dinâmica de oferta doméstica e externa.

De acordo com o argumento ricardiano de vantagens comparativas consolidado nos modelos convencionais de comércio internacional ${ }^{6}$, os países deveriam especializar-se na produção de bens em que possuem maior dotação de fatores e comercializá-los no mercado internacional, de modo a prover uma alocação mais eficiente dos recursos. As experiências históricas mostram, no entanto, que padrões sustentados de crescimento econômico estão, em geral, associados à promoção da industrialização e diversificação dos setores industriais. A consolidação de uma estrutura produtiva mais diversificada com maiores encadeamentos interindustriais permite gerar mais renda e acelerar o crescimento doméstico a partir de um estímulo de demanda inicial. Isso porque tal estrutura de oferta garante que os efeitos multiplicadores sejam transmitidos de um setor para outro ao longo da cadeia produtiva, isto é, se tornem demanda interindustrial doméstica que, na ausência de uma estrutura produtiva integrada, poderia resultar em vazamento da demanda para o exterior (ROSESTEIN-RODAN, 1943; NURKSE, 1953; HIRSCHMAN, 1958; CHENERY; CLARK, 1959; CHENERY, 1960 e 1979; CHENERY et al., 1986).

\footnotetext{
${ }^{4}$ Isso reserva à moeda um papel fundamental para o funcionamento do sistema econômico na formulação de Keynes, cujos detalhes não são abordados nesse artigo porém estão presentes em vasta literatura pós-keynesiana. Ver Keynes (1936 e 1937), Davidson (1972), Chick (1983 e 1986) e Kregel (1988), entre muitos outros.

${ }^{5}$ Para algumas discussões na literatura pós-keynesiana e desenvolvimentista sobre política econômica visando fomentar o investimento, ver Keynes (1936), Minsky (1975), Carvalho (1992), Chang (2002), Davidson (2011) e Studart (2012).

${ }^{6}$ Ver Ricardo (1817), Heckscher (1919) e Ohlin (1933).
} 
Ademais, o setor industrial cumpre papel central como fonte dinâmica de crescimento, uma vez que envolve retornos crescentes de escala e níveis mais elevados de produtividade e tecnologia que são transmitidos a outros setores. Em razão disso, o crescimento do setor industrial é visto como condição para o crescimento sustentado do produto doméstico. Nesse contexto, também é identificado na literatura um desequilíbrio estrutural de longo prazo que afeta o crescimento de economias em desenvolvimento, qual seja, o diferencial entre as elasticidades-renda da demanda desses países para exportação e importação. Dado que elas tendem a se concentrar na produção e exportação de produtos de menor valor agregado, notadamente commodities primárias, e importação de bens com maior valor agregado, como bens manufaturados, haveria uma tendência de declínio de seus termos de troca ao longo do tempo assim como restrições de balanço de pagamentos ao crescimento de mais longo prazo. Consequentemente, seria necessário promover mudanças na estrutura produtiva desses países em direção à industrialização e crescente incorporação de bens de maior valor agregado (KALDOR, 1966, 1968 e 1977; THIRLWALL, 1979; PREBISCH, 1949; SINGER, 1950).

Logo, seguindo a tradição estruturalista e pós-keynesiana-kaldoriana, os efeitos multiplicadores da demanda sobre o restante do sistema econômico dependem dos seguintes aspectos inter-relacionados: (i) do fortalecimento dos encadeamentos interindustriais e a consolidação de uma estrutura produtiva doméstica diversificada e integrada, ao invés de especializada e fragmentada, de modo a garantir complementaridade de demanda entre setores; (ii) da composição setorial da oferta, especialmente por causa propriedades pró-crescimento imbuídas nas atividades industriais; e (iii) da dinâmica entre oferta doméstica e externa a fim de consolidar em algum grau cadeias produtivas domésticas e evitar um vazamento de demanda final ou intermediária para o exterior. Portanto, o modo como a estrutura produtiva doméstica está organizada torna-se condição essencial para assegurar que estímulos de demanda, sobretudo originados a partir de novos investimentos, convertam-se em maior dinamismo econômico doméstico com menor exposição a restrições de balanço de pagamentos.

\section{Inserção externa e reformas econômicas: uma visão desenvolvimentista}

Dado que a demanda lidera o crescimento econômico e a presença de uma estrutura produtiva doméstica diversificada e integrada é importante para assegurar que os efeitos multiplicadores de geração de renda a partir da demanda agregada sejam convertidos em maior dinamismo do produto doméstico, torna-se necessário refletir sobre o tema em meio à inserção externa dos países. Há um intenso debate sobre os possíveis benefícios que as economias obteriam em termos de crescimento econômico mais elevado uma vez promovendo medidas de liberalização 
dos fluxos comerciais, produtivos e financeiros, isto é, integrando-se aos mercados internacionais. A origem deste debate remete ao fim do regime de Bretton Woods na década de 1970 e sua substituição por uma ordem internacional governada por uma agenda favorável à desregulamentação dos mercados e menor intervencionismo estatal na economia.

O aclamado “Consenso de Washington”, expressão cunhada por Williamson (1990), resume o disseminado conjunto de propostas de reformas de política econômica recomendadas sobretudo por organismos multilaterais, como o Banco Mundial e o Fundo Monetário Internacional, nos anos 1980 e 1990 para economias em desenvolvimento. O conjunto de políticas que esses países deveriam implementar inclui a eliminação de barreiras comerciais (tarifárias ou não), incentivos aos investimentos estrangeiros, liberalização financeira com desregulamentação dos mercados financeiros e cambiais domésticos bem como remoção dos controles de capitais, e redução do intervencionismo estatal na economia por meio, por exemplo, de privatizações, cortes nos gastos governamentais e abandono de políticas industriais seletivas.

Contrária aos argumentos convencionais de que abertura econômica indiscriminada resultaria em maior crescimento econômico, a visão alternativa desenvolvimentista enfatiza que tanto o processo de geração de renda a partir da demanda como as respostas compatíveis necessárias da oferta doméstica requereriam políticas nacionais ativas. A trajetória de crescimento de uma economia estaria fortemente associada ao conjunto de reformas e políticas implementadas ao longo do tempo com vistas a promover uma inserção externa que mantivesse ou incrementasse a estrutura produtiva doméstica com níveis elevados de investimento, o que não ocorreria espontaneamente a partir da livre operação das forças de mercado.

A visão desenvolvimentista apóia o argumento da indústria nascente. Isso significa que as economias não estão fadadas a se especializarem na produção de bens de acordo com suas vantagens comparativas a fim de se desenvolverem, mas, ao contrário, podem construir suas próprias habilidades e promover o desenvolvimento industrial. A consolidação dessa estrutura, no entanto, pode requerer tempo e apoio estatal, necessário para, de alguma forma, realizar, promover e coordenar investimentos entre setores e agentes econômicos. Essa visão não implica que incentivos que sejam necessários para esse processo ocorrer, como subsídios e medidas protecionistas, devam ser adotados indefinidamente. Contudo, eles podem ser necessários para desenvolver e garantir a competitividade das indústrias domésticas durante seu processo de consolidação (CHANG, 2003; CIMOLI et al., 2009).

Também apóia a regulação dos fluxos de capitais. Destaca-se, nesse quesito, a natureza especulativa do capital e a instabilidade financeira e flutuações econômicas que mercados financeiros desregulamentados e fluxos de capitais podem causar sobre a economia doméstica. 
Ainda, fluxos de capitais não necessariamente significam o financiamento de atividades produtivas. Eles incluem capital de portfólio caracterizado por sua natureza especulativa e busca de ganhos de curto prazo em mercados financeiros e cambiais ao redor do mundo. Também incluem, é verdade, investimentos diretos externos (IDE) que, entretanto, podem ou não representar criação ou ampliação de capacidade produtiva doméstica. Cabe lembrar que parte do IDE refere-se apenas a transferências patrimoniais mediante fusões e aquisições, o que não indica necessariamente maior volume de investimentos produtivos (KINDLEBERGER; ALIBER, 2011; PALMA, 2009b e 2012).

Autores desenvolvimentistas são vistos, em especial do ponto de vista de seus oponentes intelectuais, como se seus argumentos defendessem uma estratégia de desenvolvimento totalmente voltada para dentro com importância mínima destinada às transações internacionais no processo de desenvolvimento econômico. Em outras palavras, sua defesa em relação à necessidade de medidas protecionistas (como barreiras comerciais, taxa de câmbio desvalorizada, crédito subsidiado a taxa de juros favoráveis etc.) sob direção estatal para construir e consolidar uma estrutura produtiva doméstica é comumente associada a uma suposta aversão a bens e capitais estrangeiros, o que, por sua vez, tenderia a limitar a competitividade das economias. Do lado oposto, a abordagem econômica convencional é vista como em defesa de uma estratégia de desenvolvimento orientada para fora, uma vez que os países necessariamente se beneficiariam de uma maior integração junto à economia internacional.

Esse debate tem sido explorado extensivamente na literatura com base nas trajetórias contrastantes de crescimento das economias latino-americanas e asiáticas a partir dos anos 1970. A visão convencional atribui o maior dinamismo econômico do Leste Asiático, notadamente de Coréia do Sul, Taiwan, Cingapura e Hong Kong, à orientação exportadora dessas economias, consideradas como uma estratégia de desenvolvimento voltada para fora. $\mathrm{O}$ fracasso das economias latino-americanas, por sua vez, estaria associado à proteção exacerbada dos mercados e indústrias domésticos durante o período anterior de industrialização por substituição de importações (ISI) levado a cabo nos anos 1950 e 1960. Isso teria resultado no surgimento de firmas não competitivas em nível internacional, representando, assim, uma estratégia excessivamente orientada para dentro que artificialmente protegia as indústrias nacionais perante a concorrência internacional (Balassa, 1971 e 1975; Krueger, 1985 e 1995; Little et al., 1970).

A visão desenvolvimentista, contudo, destaca que houve forte intervencionismo estatal no caso das economias asiáticas. Diversos incentivos combinados com contínuo monitoramento do desempenho exportador das firmas foram utilizados a fim de promover determinadas indústrias. Ademais, o capital estrangeiro foi restrito nos estágios iniciais de industrialização e, no caso de algumas indústrias, até mais tarde. Políticas comerciais foram aplicadas em benefício das 
exportações, entendidas tanto como mercado para a produção doméstica, dado o tamanho inicial relativamente pequeno dos mercados domésticos dessas economias em termos de população e renda, como fonte de divisas para importação de bens de maior conteúdo tecnológico, especialmente bens de capitais, necessários à continuidade do processo de desenvolvimento e transformação da capacidade produtiva doméstica (AMSDEN, 1989; WADE, 1990; CHANG, 2003; RODRIK, 1994; AKYÜZ \& GORE, 1996; AKYÜZ et al., 1998; CIMOLI ET AL., 2009; PALMA, 2009a).

O desenvolvimento latino-americano, por sua vez, dependeu muito mais de uma combinação entre capital estrangeiro e esforços de coordenação estatais, o que torna controverso o argumento convencional de uma estratégia de desenvolvimento orientada para dentro. É indiscutível, no entanto, que as economias da América Latina tenham crescido rapidamente durante o período de ISI e que a proteção do mercado doméstico tenha sido uma condição necessária para o processo de industrialização, assim como foi nas experiências do Leste Asiático. Os países latino-americanos, contudo, estiveram altamente expostos a mudanças no cenário internacional, em decorrência de seu elevado grau de endividamento externo que os conduziu a crise da dívida externa no início dos anos 1980. O cenário desfavorável deu margem a aspirações neoliberais de que por meio das reformas econômicas propostas pelo "Consenso de Washington" os países conseguiriam superar seus problemas econômicos, particularmente o baixo crescimento, a inflação elevada e a alta vulnerabilidade externa (TAVARES, 1972, 1974 E 1978; PALMA, 2003, 2009A e 2012; CIMOLI et al., 2009).

Deve-se considerar, ainda, que sob uma perspectiva estruturalista o principal objetivo do processo de ISI foi promover mudanças estruturais no padrão produtivo doméstico por meio da industrialização para reduzir os diferenciais de elasticidade-renda da demanda de exportações e importações nas economias periféricas. A internalização da produção de bens manufaturados leves e pesados anteriormente importados reduziria a necessidade de divisas para a continuidade do processo de desenvolvimento das estruturas produtivas domésticas. Porém, uma vez em curso, esse processo, ao promover o crescimento, também exerceria pressão sobre divisas para importação de bens necessários ao processo produtivo que, caso não houvesse, representaria restrições ao crescimento. Consequentemente, fontes externas de financiamento, como exportações ou capital estrangeiro, seriam necessárias.

Nesse momento, cabe revisitar a literatura pós-keynesiana-kaldoriana sobre o papel desempenhado pelas exportações no crescimento de longo prazo. Kaldor era um forte defensor do desenvolvimento industrial sem objeção ao processo de ISI como forma de promoção do desenvolvimento de indústrias nascentes em setores manufatureiros leves e pesados, mas 
argumentava que proteção indiscriminada que resultasse em indústrias domésticas custosas e sem competitividade internacional, conforme experimentado por diversas economias latino-americanas nos anos 1950 e 1960, levaria a crônicas restrições de balanço de pagamentos ao crescimento. Não por acaso sua principal prescrição de política econômica para economias em desenvolvimento consistia no apoio ao processo de industrialização com crescente exportações de bens manufaturados (KALDOR, 1971 e 1974; KING, 2009 e 2010).

Sua ênfase, e também a de seus seguidores, a respeito da importância de promover as exportações difere, no entanto, dos argumentos convencionais de inserção externa. A visão de Kaldor em promover as exportações não consistia em induzir uma especialização da produção doméstica com base em suas vantagens comparativas que supostamente permitiria à economia tornar-se mais competitiva nos mercados internacionais. Ao contrário, a promoção das exportações era vista como um modo para evitar restrições ao crescimento da economia durante o processo de diversificação e consolidação da estrutura produtiva doméstica. Dado que os fluxos de capitais são pró-cíclicos e voláteis por natureza, de forma que tendem a acentuar as flutuações do crescimento doméstico ao invés de representar uma fonte estável de financiamento para acumulação de capital, as exportações, em especial de bens manufaturados, seriam responsáveis por gerar as divisas necessárias a fim de garantir as importações de bens de capitais e outros insumos intermediários para dar continuidade ao processo de desenvolvimento econômico sem restrições de balanço de pagamentos.

Em resumo, a visão desenvolvimentista está mais relacionada ao entendimento das forças motrizes do crescimento e suas limitações do que a estratégias estritamente voltadas seja para dentro, seja para fora. O investimento é entendido como motor do crescimento e condição necessária para o desenvolvimento das forças produtivas domésticas que, por sua vez, requer divisas estrangeiras, obtidas em sua maior parte mediante exportações, para evitar restrições ao crescimento, especialmente dada a necessidade de importações para se avançar na estrutura produtiva doméstica. Nesse sentido, diferentemente dos argumentos em prol de uma abertura econômica indiscriminada, políticas nacionais ativas são fundamentais para se promover uma inserção externa que garanta o desenvolvimento industrial doméstico com elevados níveis de investimento de acordo com as necessidades de cada economia em seu tempo histórico.

\section{Considerações finais}

Este artigo discute a temática do crescimento econômico, tecendo considerações para a compreensão de trajetórias sustentadas de crescimento de economias em desenvolvimento em meio à sua inserção externa. A análise combina contribuições pós-keynesianas, estruturalistas e 
desenvolvimentistas, constituindo, assim, um referencial teórico alternativo aos argumentos econômicos convencionais.

Reitera-se o papel da demanda, sobretudo do investimento, como força motriz da atividade econômica. Destaca-se a relevância do investimento seja como fonte de demanda, seja como promotor de mudanças estruturais nos padrões produtivos das economias. O investimento representa demanda corrente, mas prospectiva, acarreta efeitos de mais longo prazo em função de seu período de maturação, apresenta escala elevada e, ao mesmo tempo, é capaz de promover mudanças estruturais no sistema produtivo doméstico. Padrões sustentados de crescimento estão, portanto, associados à manutenção de níveis elevados de investimento.

Dessa forma, estímulos de demanda e seus efeitos multiplicadores são essenciais para promoção de crescimento econômico. Contudo, faz-se necessária uma estrutura de oferta capaz de assegurar que esses estímulos se traduzam em maior crescimento doméstico. Os efeitos multiplicadores da demanda sobre o restante do sistema econômico dependem de como está organizada a estrutura produtiva doméstica. Em outras palavras, dependem de encadeamentos interindustriais fortes e diversificados que garantam a complementaridade de demanda entre setores, da composição setorial da oferta em que pese a importância das atividades industriais, e da dinâmica entre oferta doméstica e externa que assegure, em grande medida, a absorção da demanda total (seja final, seja intermediária) pela oferta doméstica.

Essa temática também é discutida considerando a experiência histórica de inserção externa dos países. À luz do debate sobre crescimento entre economias asiáticas e latino-americanas, a perspectiva apresentada contrapõe-se aos argumentos convencionais de que maior abertura econômica resultaria necessariamente em maior crescimento econômico. Desloca-se o debate da dicotomia entre estratégias de desenvolvimento orientadas para fora ou para dentro para centrá-lo no entendimento das forças motrizes do crescimento e suas limitações.

Uma vez mais, destaca-se o investimento como motor do crescimento e condição necessária para o desenvolvimento das forças produtivas domésticas, porém salienta-se também a necessidade de divisas estrangeiras para garantir a continuidade do processo de transformação industrial por parte das economias em desenvolvimento com menor exposição a restrições de balanço de pagamentos. Nesse sentido, cumprem papel decisivo políticas nacionais ativas a fim de combinar formas de inserção externa com o fortalecimento da estrutura produtiva doméstica e níveis elevados de investimento e, logo, garantir padrões sustentados de crescimento econômico. 
Investimento, estrutura produtiva e inserção externa: breves considerações teóricas sobre padrões sustentados de

\section{Referências}

AKYÜZ, Y.; GORE, C. The investment-profits nexus in East Asian industrialization. World Development, v.24, n.3, pp.461-470, 1996. crossref http://dx.doi.org/10.1016/0305$\underline{750 X(95) 00154-5}$

CHANG, H.-J.; KOZUL-WRIGHT, R. New perspectives on East Asian development. Journal of Development Studies, v.34, n.6, pp.4-36, 1998. crossrefhttp://dx.doi.org/10.1080/00220389808422544

AMSDEN, A. H. Asia's next giant: South Korea and late industrialization. Oxford: Oxford University Press, 1989.

BALASSA, B. Trade policies in developing countries. American Economic Review, v.61, n.2, maio, pp.178-187, 1971.

Reforming the system of incentives in developing countries. World Development, v.3, n.6, junho, pp.365-382, 1975. cross ref $\mathrm{http} / / / \mathrm{dx}$.doi.org/10.1016/0305-750X(75)90022-4

CARVAlHO, F. J. C. de. Mr. Keynes and the Post Keynesians: principles of macroeconomics for a monetary production economy. Aldershot: Elgar, 1992.

CHANG, H.-J. Kicking away the ladder: development strategy in historical perspective. Londres: Anthem Press, 2002.

The East Asian development experience. In: CHANG, H.-J. (Ed.) Rethinking development economics. Londres: Anthem Press, pp.107-124, 2003.

CHENERY, H. B. Patterns of industrial growth. American Economic Review, v.50, n.4, setembro, pp.624-654, 1960.

Structural change and development policy. In: WORLD BANK, World Development Report, Part II, Oxford University Press, pp.44-85, 1979.

CHENERY, H. B. \& CLARK, P. G. (1959) Interindustry economics. Nova York: Wiley. ROBINSON, S. \& SYRQUIN, M. (Eds.) (1986) Industrialization and growth: a comparative study. Washington: World Bank, Oxford University Press.

CHICK, V. (1983) Macroeconomics after Keynes: a reconsideration of the General Theory. Oxford: Philip Allan.

The evolution of the banking system and the theory of saving, investment and interest. In: ARESTIS, P. \& DOW, S. (Eds.) On money, method and Keynes: selected essays of Victoria Chick. Houndmills: Macmillan, pp.196-205, 1986.

CIMOLI, M.; DOSI, G.; STIGLITZ, J. E. (Eds.) Industrial policy and development: the political economy of capabilities accumulation. Oxford: Oxford University Press, 2009. crossrefhttp://dx.doi.org/10.1093/acprof:oso/9780199235261.001.0001

DAVIDSON, P. Money and the real world. Londres: Macmillan, 1972.

Post-Keynesian macroeconomic theory: a foundation for successful economic policies for the twenty-first century, 2.ed. Cheltenham e Northampton: Edward Elgar, 2011.

HARCOURT, G. C.; KRIESLER, P. (Eds.) The Oxford handbook of Post-Keynesian economics, volume 1: theory and origins. Oxford: Oxford University Press, 2013a.. 
(Eds.) The Oxford handbook of Post-Keynesian economics, volume 2: critiques and methodology. Oxford: Oxford University Press, $2013 \mathrm{~b}$.

HECKSCHER, E. "The effects of foreign trade on the distribution of income", Ekonomisk Tidskrift, v.21, pp.497-512, 1919.

HIRSCHMAN, A. O. The strategy of economic development. New Haven: Yale University Press, 1958.

KALDOR, N. Causes of the slow rate of economic growth of the United Kingdom. Cambridge University Press, 1966.

Productivity and growth in manufacturing industry: a reply. Economica, New Series, v.35, n.140, novembro, pp.385-391, 1968. crossrefhttp://dx.doi.org/10.2307/2552347

Conflicts in national economic objectives. Economic Journal, v.81, n.321, março, pp.1-16, 1971. crossref http://dx.doi.org/10.2307/2229754

The role of industrialization in Latin American inflation. In: GEITHMAN, D. T. (Ed.) Fiscal policy for industrialization and development in Latin America. Gainesville: University of Florida Press, pp.14-28, 1974.

Capitalism and industrial development: some lessons from Britain's experience.

Cambridge Journal of Economics, v.1, n.2, jun, pp.193-204, 1977.

KEYNES, J. M. The general theory of employment, interest and money. Vol.VII of The collected writings of John Maynard Keynes. Cambridge: Cambridge University Press for the Royal Economic Society, 2013.

The general theory of employment", Quarterly Journal of Economics, v.51, n.2, fevereiro, pp.209-223, 1937. crossref http://dx.doi.org/10.2307/1882087

KINDLEBERGER, C. P. \& ALIBER, R. Z. Manias, panics and crashes: a history of financial crises, $6^{\text {a }}$ ed. Basingstoke: Palgrave Macmillan, 2011.

KING, J. E. A history of Post-Keynesian economics since 1936. Cheltenham e Northampton: Edward Elgar, 2002.

Nicholas Kaldor. Basingstoke: Palgrave Macmillan, 2009.

Kaldor and the Kaldorians. In: SETTERFIELD, M. (Ed.) Handbook of alternative theories of economic growth. Cheltenham e Northampton: Edward Elgar, pp.157-172, 2010. crossrefhttp://dx.doi.org/10.4337/9781849805582

(Ed.) The Elgar companion to Post-Keynesian economics, 2. ed. Cheltenham e Northampton: Edward Elgar, 2012.

KREGEL, J. A. The multiplier and liquidity preference: two sides of the theory of effective demand. In: BARRÈRE, A. (Ed.) The foundations of Keynesian analysis. Londres: Macmillan, 1988.

KRUEGER, A. O. The experience and lessons of Asia's super exporters. In: CORBO, V.; KRUEGER, A. O. \& OSSA, F. J. (Eds.) Export-oriented development strategies: the success of five newly industrializing countries. Boulder: Westview Press, pp.187-212,1985.

Institution, 1995.

Trade policies and developing nations. Washington: The Brookings 
LITTLE, I.; SCITOVSKY, T. \& SCOTT, M. Industry and trade in some developing countries: a comparative study. Londres: Oxford University Press, 1970.

MINSKY, H. P. John Maynard Keynes. Nova York: Columbia University Press, 1919.

NURKSE, R. Problems of capital formation in underdeveloped countries. Oxford e Nova York: Oxford University Press, 1953.

OHLIN, B. Interregional and international trade. Cambridge: Harvard University Press, 1933.

PALMA, J. G. "The Latin American economies during the second half of the twentieth century: from the age of 'ISI' to the age of 'the end of history"'. In: CHANG, H.-J. (Ed.) Rethinking development economics. Londres: Anthem Press, pp.125-151,2003.

Flying geese and waddling ducks: the different capabilities of East Asia and Latin America to 'demand-adapt' and 'supply-upgrade' their export productive capacity. In: CIMOLI, M.; DOSI, G. \& STIGLITZ, J. (Eds.) Industrial policy and development: the political economy of capabilities accumulation. Oxford: Oxford University Press, pp.203-238, 2009a. crossrefhttp://dx.doi.org/10.1093/acprof:oso/9780199235261.001.0001

The revenge of the market on the rentiers: why neoliberal reports of the end of history turned out to be premature, Cambridge Working Papers in Economics (CWPE), n.0927, dezembro 2009b.

"How the full opening of the capital account to highly liquid financial markets led Latin America to two and a half cycles of 'mania, panic and crash", Cambridge Working Papers in Economics (CWPE), n.1201, janeiro 2012.

PASINETTI, L. L. Keynes and the Cambridge Keynesians: a 'revolution in economics' to be accomplished. Cambridge: Cambridge University Press, 2007.

PREBISCH, R. The economic development of Latin America and its principal problems. Do original em espanhol "El desarrollo económico de América Latina y algunos de sus principales problemas". Lake Success: United Nations, 1950.

RICARDO, D. On the principles of political economy and taxation. Londres: Murray, 3. ed., 1821.

RODRIK, D. "Getting interventions right: how South Korea and Taiwan grew rich", Working Paper Series, n.4964, National Bureau of Economic Research (NBER), Cambridge, dezembro 1994.

ROSENSTEIN-RODAN, P. N. Problems of industrialisation of Eastern and South-Eastern Europe. Economic Journal, v.53, n.210/211, junho-setembro, pp.202-211.

SINGER, H. W. The distribution of gains between investing and borrowing countries. American Economic Review, v.40, n.2, maio, pp.473-485, 1950.

STUDART, R. Development finance. In: KING, J. E. (Ed.) The Elgar companion to PostKeynesian economics, 2. ed. Cheltenham e Northampton: Edward Elgar, pp.127-131,2012.

TAVARES, M. da C. Da substituição de importações ao capitalismo financeiro. Rio de Janeiro: Zahar, 1972.

1998.

Acumulação de capital e industrialização no Brasil. Campinas: IE-Unicamp, 3. ed., 
Ciclo e crise: o movimento recente da industrialização brasileira. Campinas: IEUnicamp, 1998.

THIRLWALL, A. P. "The balance of payments constraint as an explanation of international growth rate differences”, Banca Nazionale del Lavoro Quarterly Review, v.128, pp.45-53, 1979.

WADE, R. Governing the market: economic theory and the role of government in East Asian industrialization. Princeton: Princeton University Press, 1990.

WILLIAMSON, J. "What Washington means by policy reform”. In: WILLIAMSON, J. (Ed.) Latin American adjustment: how much has happened? Washington: Institute for International Economics, pp.7-20, 1990. 